\title{
Emergency department length of stay for patients requiring mechanical ventilation: a prospective observational study
}

Louise Rose ${ }^{1 *}$, Sara Gray ${ }^{2}$, Karen Burns ${ }^{3}$, Clare Atzema ${ }^{4}$, Alex Kiss ${ }^{5}$, Andrew Worster ${ }^{6}$, Damon C Scales ${ }^{4}$, Gordon Rubenfeld ${ }^{4}$ and Jacques Lee ${ }^{4}$

\begin{abstract}
Background: Recommendations for acceptable emergency department (ED) length of stay (LOS) vary internationally with $\leq 8 \mathrm{~h}$ generally considered acceptable. Protracted ED LOS may place critically ill patients requiring mechanical ventilation at increased risk of adverse events as most EDs are not resourced for longitudinal delivery of critical care. Our objective was to quantify the ED LOS for mechanically ventilated patients (invasive and/ or non-invasive ventilation [NIV]) and to explore patient and system level predictors of prolonged ED LOS. Additionally, we aimed to describe delivery and monitoring of ventilation in the ED.

Methods: Prospective observational study of ED LOS for all patients receiving mechanical ventilation at four metropolitan EDs in Toronto, Canada over two six-month periods in 2009 and 2010.

Results: We identified 618 mechanically ventilated patients which represented $0.5 \%$ (95\% Cl 0.4\%-0.5\%) of all ED visits. Of these, 484 (78.3\%) received invasive ventilation, 118 (19.1\%) received NIV; 16 received both during the ED stay. Median Kaplan-Meier estimated duration of ED stay for all patients was $6.4 \mathrm{~h}$ (IQR 2.8-14.6). Patients with trauma diagnoses had a shorter median (IQR) LOS, $2.5 \mathrm{~h}$ (1.3-5.1), compared to ventilated patients with non-trauma diagnoses, $8.5 \mathrm{~h}(3.3-14.0)(p<0.001)$. Patients requiring NIV had a longer ED stay $(16.6$ h, 8.2-27.9) compared to those receiving invasive ventilation exclusively $(4.6 \mathrm{~h}, 2.2-11.1)$ and patients receiving both $(15.4 \mathrm{~h}, 6.4-32.6)$ ( $p<0.001)$. Longer ED LOS was associated with ED site and lower priority triage scores. Shorter ED LOS was associated with intubation at another ED prior to transfer.

Conclusions: While patients requiring mechanical ventilation represent a small proportion of overall ED visits these critically ill patients frequently experienced prolonged ED stay especially those treated with NIV, assigned lower priority triage scores at ED presentation, and non-trauma patients.
\end{abstract}

Keywords: Mechanical ventilation, Emergency department, Non-invasive ventilation, critical illness, Acute respiratory failure

\section{Background}

Rising demand for emergency department (ED) services and the relative shortage of hospital beds are major contributors to ED crowding and result in protracted ED length of stay (LOS) [1]. Delayed admission to an intensive care unit (ICU) from the ED may occur due to hospital crowding and a lack of available ICU beds $[1,2]$.

\footnotetext{
* Correspondence: louise.rose@utoronto.ca

'Lawrence S. Bloomberg Faculty of Nursing, 155 College St, Rm 276, Toronto, ON M5T IP8, Canada

Full list of author information is available at the end of the article
}

ED crowding due to a lack of hospital beds is a global problem [3]. In the US, the proportion of critically ill patients presenting to EDs is rising and their ED LOS is increasing [4-6].

Management of critical illness is highly resource intensive and time-sensitive [7]. Among patients who present to an ED, critically ill ventilated patients require a high level of care and are at high risk of adverse events. Expedited admission (under $2 \mathrm{~h}$ ) from the ED to the ICU of critically ill ventilated patients has been associated with shorter durations of mechanical

\section{Biomed Central}

(c) 2012 Rose et al.; licensee BioMed Central Ltd. This is an Open Access article distributed under the terms of the Creative Commons Attribution License (http://creativecommons.org/licenses/by/2.0), which permits unrestricted use, distribution, and reproduction in any medium, provided the original work is properly cited. 
ventilation and ICU LOS [8]. Insufficient monitoring and/or substandard management of these patients may pose a substantial threat to patient safety, leading to complications and adverse outcomes. Key quality of care measures may be difficult to implement in the busy ED setting. Examples of these measures include patient repositioning to reduce atelectasis and semi-recumbent positioning and provision of oral hygiene to prevent ventilator associated pneumonia [9]. Most EDs do not have resources for longitudinal critical care delivery such as uninterrupted 1:1 nurse-to-patient ratios [10], and availability of respiratory therapists (RTs), subspecialty expertise, and invasive hemodynamic monitoring.

Our objective was to quantify the ED LOS for patients requiring invasive and non-invasive ventilation (NIV) in four EDs and to explore patient and system level predictors of prolonged ED LOS. Additionally, we aimed to describe practices of delivery and monitoring of ventilation in the ED.

\section{Methods \\ Study design and setting}

We conducted a six-month prospective observational study of mechanical (invasive and NIV) ventilation utilization at four metropolitan EDs in Toronto, Canada. Two EDs were located in large community teaching hospitals and each had an annual census of over 65,000 patients. The other two EDs were in university-affiliated hospitals with regional trauma center designation and had an annual census of over 40,000 patients each. The interprofessional team of the four EDs included RTs, allied health professionals trained in the management of ventilation, who attended intubation and initiation of ventilation and were available on call if needed. The study was approved by the Research Ethics Boards (REB) of all participating hospitals (Saint Michael's Hospital, Sunnybrook Health Sciences Centre, Toronto East General Hospital and Saint Joseph's Hospital) and the University of Toronto who together waived the requirement for consent due to the observational nature of the study. All data were collected in an anonymized fashion and stored in a locked research office and on a secure computer server.

\section{Study population}

We collected data on consecutive adult patients aged 16 and over who received invasive (endotracheal tube or tracheostomy) and/or NIV (administered by mask) mechanical ventilation. For feasibility reasons such as timing of REB approvals and availability of research personnel, data were collected from January to July 2009 at two sites and August 2009 to January 2010 at the remaining two EDs. For patients with multiple ED presentations, we included data from the first ED presentation only.

\section{Data collection}

Mechanically ventilated patients were identified by the treating respiratory therapists (RTs) during the ED visit. RTs notified the study team of patient enrolment by telephone and completed a short data collection form identifying the primary reason for ventilation, time of intubation and initiation of mechanical ventilation (invasive or non-invasive), type of monitoring used, reasons for delayed discharge, and disposition location. Admission logs of hospital departments likely to receive ventilated patients from the ED were screened to identify missed patients.

We collected demographic data, Canadian Triage Acuity Scale (CTAS) score assigned by the triage nurse on ED presentation, location of intubation, requirements for sedation and vasopressors, worst (furthest from normal) systolic blood pressure, heart rate and oxygenation saturation during ED stay, ED time indicators (triage, registration, departure readiness, and departure), and ED discharge diagnoses. ED discharge delay was determined when the difference between ED departure readiness and ED departure exceeded $6 \mathrm{~h}$. A CTAS score of 1 represents a patient requiring immediate assessment and intervention, CTAS 2 patients have a maximal wait time for assessment by a physician of $15 \mathrm{~min}$, and patients triaged as CTAS 3 require assessment within $30 \mathrm{~min}$ [11]. ED discharge diagnoses were later classified according to the Canadian Emergency Department Diagnoses Shortlist [12].

We followed patients to determine the duration of mechanical ventilation, ICU (where applicable) and hospital LOS, and vital status at discharge. The duration of ventilation was defined as the time from initiation in a participating ED until either successful extubation, disconnection from positive pressure ventilation for tracheostomized patients, death, or transfer to another institution. We also collected initial ventilator settings, any ventilator adjustments performed in ED, and arterial blood gas (ABG) values before and after mechanical ventilation initiation. For patients receiving NIV, the number of times NIV was discontinued and reinitiated and the reason for discontinuation were recorded. We summed the duration of each NIV episode to obtain the total duration of NIV in the ED. ED demographic data and six-month summary activity statistics, obtained from ED directors and ED information systems respectively, were also captured.

\section{Data analysis}

We summarized continuous variables using means and standard deviations or medians and interquartile ranges 
depending on the data distribution and categorical variables using proportions and their 95\% confidence intervals (CI). We calculated the ED LOS using time-toevent methods (survival analysis), with censoring of deaths, for (1) all patients, and (2) excluding trauma diagnoses. We compared differences between groups using the log-rank test. We constructed a Cox proportional hazard model to estimate the effect of selected covariates on the time to ED discharge for non-trauma patients receiving only invasive ventilation. We excluded trauma patients from our model due to the presence of trauma activation protocols designed to reduce ED LOS in the two designated trauma centres. The Cox model included covariates representing patient demographics and a priori selected variables deemed likely to be associated with ED LOS or showing bivariate associations $(\mathrm{p}<0.10)$ and adjusted for the correlation among patients in the same hospital. We calculated the relative risk (RR) of an ED 'discharge delay', defined as the time between discharge readiness and physical departure, of $>24 \mathrm{~h}$ for invasively ventilated patients compared to those receiving NIV and both forms of ventilation. Variables likely to be associated with ABG measurement in the ED (binary of yes/no) after commencement of ventilation (ED LOS, ventilation type, and primary reason for ventilation) were selected a priori and examined using multiple logistic regression. The model was assessed for collinearity and goodness of fit [13]. All tests were two-tailed and we considered a p-value of 0.05 as statistically significant. Analyses were performed using SPSS 18.0 (SPSS, Chicago, IL, USA) and SAS 9.1 (SAS Institute, Cary, NC, USA).

\section{Results}

\section{Patient characteristics}

We recorded data on 618 patients receiving ventilation in the ED representing 631 ED presentations; 484 (78.3\%) patients received invasive ventilation only, 118 (19.1\%) NIV; 16 (2.6\%) patients received both. These 618 patients represented $0.5 \%$ (95\% CI $0.4-0.5)$ of the 135,352 patients seen at participating EDs during the study period; $353 / 1,828$ (19.3\% [95\% CI 17.5-21.1]) CTAS 1 patients, 237/25,724 (0.9\%, [0.8-1.0]) CTAS 2, and $26 / 71,502(0.04 \%$ [0.03-0.05]) CTAS 3 patients $(2 /$ 618, $0.3 \%$ not reported).

We present patient demographics according to type of ventilation in Table 1 . Of the 367 patients presenting to EDs with trauma center designation, head injury (118, $32.2 \%$ [27.4-36.9]), trauma without head injury (40, $10.9 \%$ [7.7-14.1]), and primary neurologic disorder (67, 18.3\% [14.3-22.2]) were the most frequent indications for invasive ventilation. In the two community EDs, cardiac arrest $(30 / 117,25.6 \%$ [17.7-33.6]), overdose (26,
Table 1 Patient Characteristics

\begin{tabular}{|c|c|c|c|}
\hline & $\begin{array}{l}\text { MV only } \\
(n=484)\end{array}$ & $\begin{array}{l}\text { NIV only } \\
(n=118)\end{array}$ & $\begin{array}{l}\text { Both } \\
(n=16)\end{array}$ \\
\hline Age, median (IQR) & $58(41-76)$ & $76(64-84)$ & $72(62-81)$ \\
\hline Male gender & $307(63.4)$ & $64(54.2)$ & $8(50.0)$ \\
\hline \multicolumn{4}{|l|}{ CTAS codes ${ }^{a}$} \\
\hline 1 & $326(67.4)$ & $22(18.6)$ & $5(31.3)$ \\
\hline 2 & $139(28.7)$ & $87(73.7)$ & $11(68.8)$ \\
\hline 3 & $19(3.9)$ & $7(5.9)$ & - \\
\hline Not reported & - & $2(1.7)$ & - \\
\hline \multicolumn{4}{|c|}{ Reason for mechanical ventilation } \\
\hline Trauma with head injury & $123(25.4)$ & $2(1.7)$ & - \\
\hline Primary neurologic disorder & $80(16.5)$ & $2(1.7)$ & $1(6.3)$ \\
\hline Cardiac/respiratory arrest & $61(12.6)$ & - & $1(6.3)$ \\
\hline Trauma (not including head) & $43(8.9)$ & - & - \\
\hline Overdose & $40(8.3)$ & $1(0.8)$ & - \\
\hline Pneumonia & $34(7.0)$ & $12(10.2)$ & $2(12.5)$ \\
\hline Acute respiratory failure ${ }^{b}$ & $34(7.0)$ & $19(16.1)$ & $1(6.3)$ \\
\hline Heart failure & $12(2.5)$ & $45(38.1)$ & $4(25.0)$ \\
\hline Sepsis and septic shock & $29(6.0)$ & - & $2(12.5)$ \\
\hline COPD exacerbation & $7(1.4)$ & $35(29.7)$ & $4(25.0)$ \\
\hline NMD & $4(0.8)$ & - & $1(6.3)$ \\
\hline Asthma & $1(0.2)$ & $2(1.7)$ & - \\
\hline Other & $16(3.3)$ & - & - \\
\hline
\end{tabular}

All values are $\mathrm{n}(\%)$ unless indicated.

$\mathrm{CTAS}=$ Canadian triage and acuity scale, $\mathrm{COPD}=$ chronic obstructive pulmonary disorder, NMD = neuromuscular disease, $\mathrm{MV}=$ mechanical ventilation (invasive), NIV = non-invasive ventilation.

${ }^{a}$ CTAS score of 1 represents a patient requiring immediate assessment and intervention, CTAS 2 patients have a maximal wait time for assessment by a physician of $15 \mathrm{~min}$, and patients triaged as CTAS 3 require assessment within 30 min. [11].

${ }^{\mathrm{b}}$ Excludes patients with pneumonia, COPD exacerbation and asthma.

22.2\% [14.7-29.8]), and acute respiratory failure (14, $12.0 \%[6.1-17.9])$ were the most frequent indications.

\section{ED length of stay}

Kaplan-Meier estimated median (IQR) duration of ED stay for all patients was $6.4 \mathrm{~h}(2.8-14.6)$. Of the 618 patients, 237 (38.4\% [34.5-42.2]) had a total ED LOS longer than $6 \mathrm{~h}$ but less than $24 \mathrm{~h}$ and 71 (11.5\% [9.011.0]) had a total ED LOS longer than $24 \mathrm{~h}$. Patients presenting to an ED requiring NIV had a longer median (IQR) duration of ED stay; $16.6 \mathrm{~h}$ (8.2-27.8) compared to $4.6(2.2-5.3)$ hours for those receiving invasive mechanical ventilation exclusively and $15.4 \mathrm{~h}$ (6.4-32.6) for patients receiving both $(p<0.001)$ (Figure 1$)$. Median ED LOS differed according to site (range 3.7 to $14.4 \mathrm{~h}$ for invasively ventilated patients $[p<0.001]$ and 11.4 to $29.8 \mathrm{~h}$ for NIV patients $[p<0.001])$. Patients with trauma diagnoses had a shorter median (IQR) LOS, $2.5 \mathrm{~h}$ (1.3-5.1), compared to ventilated patients with non- 


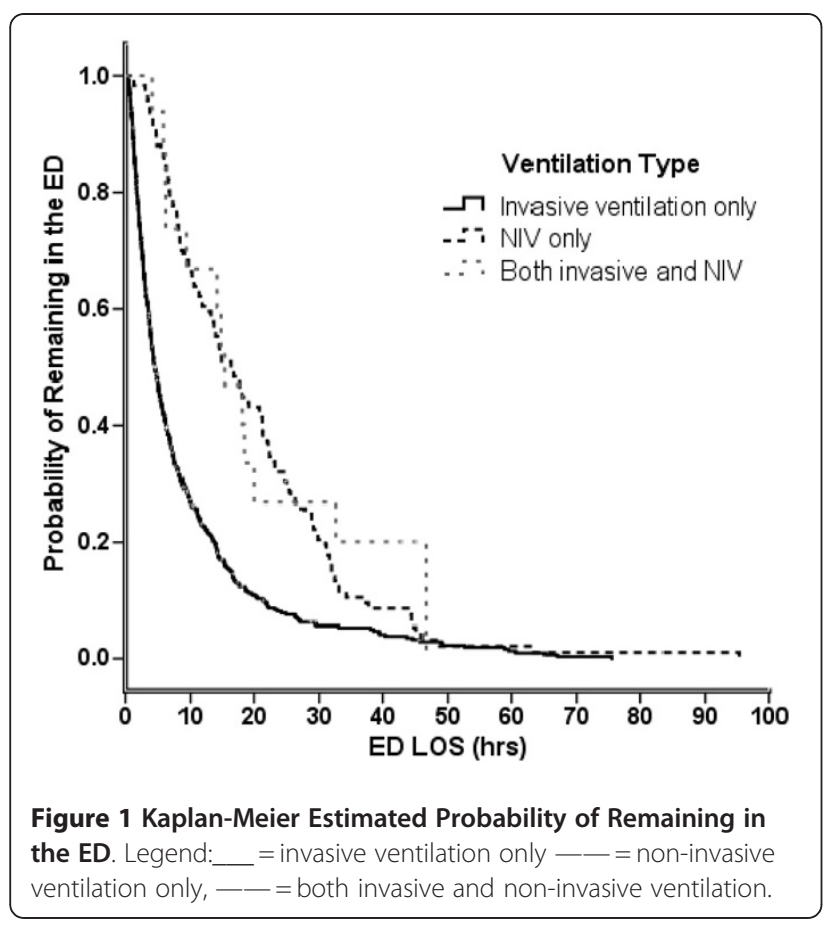

trauma diagnoses, $8.5 \mathrm{~h}(3.3-14.0)(p<0.001)$. Patients initially triaged as CTAS 3 were more likely to remain longer in the ED whereas those intubated at another ED prior to transfer had a shorter ED LOS after adjusting for age, gender and reason for ventilation (Table 2).

'Discharge delay' $>6 \mathrm{~h}$ but $\leq 24 \mathrm{~h}$ was experienced by 97 (15.7\% [12.8-18.6]) patients. Discharge delay $>24 \mathrm{~h}$ was experienced by 46 (7.4\% [5.4-9.5]) patients. Patients receiving NIV or both forms of ventilation were more likely to experience a discharge delay $>24 \mathrm{~h}$ compared to patients receiving only invasive ventilation, RR 4.1 (95\% CI 2.3-7.3) and RR 5.8 (95\% CI 2.2-14.8), respectively. The primary reason for discharge delay for patients receiving invasive ventilation was lack of an available ICU bed ( 55 of 64 patients that had reason for discharge delay reported, $85.9 \%$ [75.4-92.4]). The primary reason for discharge delay for NIV patients was awaiting treatment decision (34/60, 56.7\% [44.1-68.4]; lack of available in-patient bed was identified for 23/60 (38.3\% [27.1-51.0] patients. Patients receiving invasive ventilation in the ED remained in hospital for a median (IQR) of 16.4 days (5.4-38.7), NIV 8.8 days (4.3-21.2) and those receiving both invasive and NIV 22.4 days (10.728.5) $(\mathrm{p}<0.001)$.

Hospital mortality was $36.1 \%$ (95\% CI 32.2-39.9). ED and hospital discharge outcomes are shown in Table 3.

\section{Ventilation and monitoring}

Pressure control modes were used most frequently 230/ 500 (46.0\% [41.6-50.4]) during invasive mechanical ventilation, followed by Assist Control (volume) 180/500
Table 2 Factors affecting ED LOS for Invasively Ventilated Non-Trauma Patients

\begin{tabular}{|c|c|c|c|c|}
\hline & \multicolumn{2}{|c|}{ Discharge ED Alive } & \multirow{2}{*}{$\begin{array}{l}\text { Univariate } \\
\text { HR }[95 \% \mathrm{Cl}]\end{array}$} & \multirow{2}{*}{$\begin{array}{l}\text { Multivariate } \\
\text { HR }[95 \% \mathrm{Cl}] \\
\end{array}$} \\
\hline & $n / N$ & $\%[95 \% \mathrm{Cl}]$ & & \\
\hline Age & - & - & $1.0[1.0-1.0]$ & $1.0[1.0-1.0]$ \\
\hline Male gender & $176 / 192$ & 92 [87-95] & $1.0[0.8-1.2]$ & $1.0[0.8-1.2]$ \\
\hline \multicolumn{5}{|l|}{ Triage code } \\
\hline CTAS 1 & 158/177 & 89 [84-93] & 1 & 1 \\
\hline CTAS 2 & $116 / 121$ & 96 [91-98] & $0.8[0.6-1.1]$ & $0.8[0.6-1.3]$ \\
\hline CTAS 3 & $17 / 19$ & 89 [69-97] & $0.4[0.3-0.6]$ & $0.3[0.2-0.4]$ \\
\hline \multicolumn{5}{|l|}{ Location of intubation } \\
\hline Study ED & $215 / 228$ & 94 [90-97] & 1 & 1 \\
\hline Other ED & $25 / 25$ & $100[-]$ & $6.1[3.0-12.3]$ & $8.4[5.4-12.9]$ \\
\hline EMS & $43 / 56$ & 77 [64-86] & $1.3[0.8-2.1]$ & $1.5[1.0-2.4]$ \\
\hline \multicolumn{5}{|c|}{ Reason for ventilation } \\
\hline Respiratory/cardiac & $112 / 117$ & 96 [90-98] & 1 & 1 \\
\hline Neurological & $116 / 120$ & 97 [92-99] & $1.2[0.8-1.7]$ & $0.9[0.7-1.2]$ \\
\hline Cardiac arrest & $44 / 60$ & 73 [61-83] & $0.8[0.4-1.6]$ & $0.9[0.5-1.8]$ \\
\hline Other & $19 / 20$ & 95 [76-99] & $1.0[0.7-1.4]$ & $1.0[0.8-1.2]$ \\
\hline
\end{tabular}

$\mathrm{ED}=$ emergency department, $\mathrm{HR}=$ hazard ratio, $\mathrm{Cl}=$ confidence interval, $\mathrm{CTAS}=$ Canadian triage and acuity scale, EMS = emergency medical services $n / N$ refers to the number of patients with the identified characteristic (e.g. male gender) that were discharged alive from the ED out of the total number of patients in the study with the same characteristic.

A hazard ratio of $>1$ reflects a greater likelihood of discharge and hence a shorter length of stay.

Table 3 Emergency Department and Hospital Discharge Destinations

\begin{tabular}{|c|c|c|c|}
\hline Discharge Destinations & $\begin{array}{l}\text { MV only } \\
(n=484)\end{array}$ & $\begin{array}{l}\text { NIV only } \\
(n=118)\end{array}$ & $\begin{array}{l}\text { Both } \\
(n=16)\end{array}$ \\
\hline \multicolumn{4}{|l|}{ From the ED } \\
\hline Intensive care unit & $327(67.6)$ & $20(17.0)$ & $9(56.3)$ \\
\hline Operating room & $45(9.3)$ & - & - \\
\hline Death & $33(8.8)$ & $5(4.2)$ & $3(18.8)$ \\
\hline Other hospital & $33(6.8)$ & - & $1(6.3)$ \\
\hline General floor $^{a}$ & $17(3.9)$ & $67(56.8)$ & $2(12.5)$ \\
\hline Coronary care/high dependency unit & $18(3.5)$ & $22(18.6)$ & $1(6.3)$ \\
\hline Home $^{a}$ & $11(2.3)$ & $4(3.4)$ & - \\
\hline From the hospital & $(n=406)$ & $(n=109)$ & $(n=12)$ \\
\hline Home & $160(39.4)$ & $63(57.8)$ & $6(50.0)$ \\
\hline Death & $146(36.0)$ & $29(26.6)$ & $5(41.7)$ \\
\hline Other acute care hospital & $38(9.4)$ & $7(6.4)$ & - \\
\hline Rehabilitation & $35(8.6)$ & $2(1.8)$ & $1(8.3)$ \\
\hline Long term care facility & $21(5.2)$ & $4(3.7)$ & - \\
\hline Not available & $6(1.5)$ & $4(3.7)$ & - \\
\hline
\end{tabular}

$\mathrm{MV}=$ mechanical ventilation (invasive), NIV = non-invasive ventilation, $\mathrm{ED}=$ emergency department.

${ }^{a}$ Of the 27 patients discharge to the floor or home, the 3 main indications for ventilation were overdose $(12,44.4 \%)$, trauma $(8,29.6 \%)$ and cardiac arrest $(3,11.1 \%)$. 
(36.0\% [31.8-40.2]) and spontaneous modes 58/500 (11.6\% [8.8-14.4]) (missing for 32 patients). NIV was administered as noninvasive positive-pressure ventilation (NPPV) using an oro-nasal face mask for all patients. Twenty-seven (20.1\% [13.4-26.9]) NIV patients refused invasive ventilation, of whom 13 (48.1\% [29.3-67.0]) survived to admission but died in hospital. Twelve patients required a recommencement of NIV in the ED after initial discontinuation. Of the 16 patients receiving both types of ventilation, 14 received NIV prior to intubation constituting a NIV failure rate of 14/134 (10.5\% [5.3-15.6]). Congestive heart failure and chronic obstructive pulmonary disease were the primary reasons for NIV in $8(57.1 \%$ [32.6-78.6]) of these patients. The median (IQR) time from NIV initiation to intubation was $1.25 \mathrm{~h}$ (1.25-5.0). The remaining two patients received NIV after extubation in the ED.

ABG measurement following commencement of ventilation was performed on 341/618 (55.2\%) patients. The median (IQR) time until availability of ABG results from commencement of invasive or NIV was $88 \mathrm{~min}$ (38190). The likelihood of ABG measurement was influenced by site, ED LOS, neurological impairment for reasons other than trauma, and ventilation type (Table 4). Of the 277 patients without ABG assessment in the ED, 76 (27.4\% [22.2-32.7]) had end-tidal $\mathrm{CO}_{2}$ monitoring, and all patients had oxygen saturation monitoring. For patients presenting to an ED with traumatic brain injury, 7/99 (7.1\% [2.0-12.1]) had an initial $\mathrm{PaCO}_{2} \leq 30 \mathrm{mmHg}$ and $16 / 99(16.2 \%$ [8.9-23.4]) $>49 \mathrm{mmHg}$.

Table 4 Arterial Blood Gas Analysis in the ED

\begin{tabular}{|c|c|c|c|c|}
\hline & \multicolumn{2}{|l|}{ No $A B G$} & \multirow{2}{*}{$\begin{array}{l}\text { Univariate } \\
\text { OR }[95 \% \mathrm{Cl}]\end{array}$} & \multirow{2}{*}{$\begin{array}{l}\text { Multivariate } \\
\text { OR }[95 \% \mathrm{Cl}]\end{array}$} \\
\hline & $n / N$ & $\%[95 \% \mathrm{Cl}]$ & & \\
\hline \multicolumn{5}{|l|}{ Site } \\
\hline ED1 & $73 / 222$ & 33 [27-39] & 1 & 1 \\
\hline ED2 & $119 / 199$ & 60 [53-67] & $3.0[2.0-4.5]$ & $2.5[1.6-3.9]$ \\
\hline ED3 & $65 / 99$ & 66 [56-75] & $3.9[2.4-6.4]$ & $3.7[2.1-6.7]$ \\
\hline ED4 & $20 / 98$ & 20 [12-28] & $0.5[0.3-0.9]$ & $0.6[0.3-1.2]$ \\
\hline ED LOS (h) & - & - & $1.0[0.9-1.0]$ & $1.0[0.9-1.0]$ \\
\hline \multicolumn{5}{|l|}{ Ventilation type } \\
\hline Invasive & $215 / 484$ & 44 [40-49] & 1 & 1 \\
\hline Non-invasive & $54 / 118$ & 46 [37-55] & $1.1[0.7-1.6]$ & $1.6[0.8-3.3]$ \\
\hline Both & $8 / 16$ & $50[26-75]$ & $1.3[0.5-3.4]$ & $5.3[1.5-19.2]$ \\
\hline \multicolumn{5}{|l|}{ Reason for ventilation } \\
\hline Respiratory/cardiac & $70 / 182$ & $39[31-46]$ & 1 & 1 \\
\hline Trauma & $65 / 168$ & $39[31-46]$ & $1.0[0.7-1.6]$ & $0.9[0.6-1.6]$ \\
\hline Neurological & $66 / 124$ & 53 [45-62] & $1.8[1.1-2.9]$ & $1.9[1.1-3.3]$ \\
\hline Cardiac arrest & $32 / 62$ & 20 [14-26] & $1.7[1.0-3.1]$ & $1.9[1.0-3.9]$ \\
\hline Other & $12 / 21$ & 57 [36-78] & $2.1[0.9-5.3]$ & $2.4[0.9-6.5]$ \\
\hline
\end{tabular}

$\mathrm{ABG}=$ arterial blood gas, $\mathrm{OR}=$ odds ratio, $\mathrm{Cl}=$ confidence interval

$\mathrm{ED}=$ emergency department, $\mathrm{LOS}=$ length of stay.

\section{Discussion}

Our results indicate that while ventilated patients represent a small proportion of ED visits, they are not a 'rare' event and remain in the ED for prolonged periods of time, given the resource intensive nature of their care. ED LOS for patients requiring NIV was substantially longer than for patients receiving invasive ventilation exclusively. During stabilization of NIV patients appropriate disposition may be difficult to determine in that it may be unclear if the patient requires admission to ICU or to a step-down unit or floor. This may contribute to prolonged ED LOS as admitting teams (ICU and non-ICU) may delay patient acceptance until the patient's response to NIV is ascertained. Additionally options for provision of NIV outside of ED and the ICU may be limited. In our study sites, one ED could not provide NIV in an alternative setting other than ICU; disposition options were limited to coronary care and step down units in the remaining EDs. Review of admission pathways for these patients and consideration for provision of NIV on general floors may be warranted.

A substantial number of patients experienced delayed departure from the ED after being deemed departure ready. Delays in hospital admission contribute to ED crowding and jeopardize the safety and quality of care delivered to both critically and non-critically ill patients. EDs often lack the resources and personnel trained in the longitudinal management of the critically ill [14-16]. Training of ED physicians and nurses in the ongoing management of ventilated patients is generally limited [17]. In North America, mechanical ventilation is initiated by RTs, who typically leave the ED once the patient has been stabilized and return for reassessment and to facilitate transfers, at the request of medical or nursing staff. Together, these factors may result in ventilated patients in the ED receiving suboptimal and interrupted care. Similarly, in countries that do not utilize RTs such as Europe, Scandinavia, the United Kingdom, and Australasia clinicians specialized in the management of ventilation may not be present in the ED at all times.

Protracted ED LOS is a marker of hospital access block and ED crowding and may increase hospital mortality for critically ill and non-critically ill patients [2,18-24]. Hospital LOS and mortality for our patient cohort were similar to those reported in a large international cohort study of patients receiving mechanical ventilation in the ICU [25] and comparable to the ICU mortality rate reported in a multi-center Canadian cohort study [26]. We did not specifically examine the relationship between hospital mortality and ED LOS due to the lack of validated and reliable tools to measure illness severity in the ED [27]. Future studies are 
required to develop and validate ED illness severity measures to enable characterization of the association between ED LOS and hospital mortality for critically ill patients.

In our study ED LOS for patients with non-trauma diagnoses differed according to site, CTAS score, and the location of intubation. Differences across sites likely reflect differences in ICU and hospital capacity and potentially modifiable bed management practices, while CTAS scores reflect differences in patient acuity. Detecting differences across sites may assist with identification of modifiable risk factors and best practices that can be transferred to other institutions. Patients transferred from an ED other than a study ED experienced shorter ED stays as presumably these were anticipated transfers for specialized services within tertiary care centers.

We noted a preference for pressure control ventilation modes for all patient indications. Clinicians may prefer for this ventilation style due to the decelerating flow pattern and ability to limit inspiratory pressures [28-30]. Ventilator induced lung injury may result from choice of ventilation modes or strategies that do not limit inspiratory pressures and deliver tidal volumes based on predicted body weight $[31,32]$. We were unable to calculate tidal volume by predicted or actual body weight as patient height and weight were rarely documented either on our case report forms or on documents used by participating EDs and ICUs. It is unclear if this indicates clinicians were not targeting tidal volume to predicted body weight or if it reflects a need to revise ventilation charting in the ED.

Recommendations for ABG sampling state ABGs should quantitate the response to therapeutic interventions such as mechanical ventilation [33]. Only $55 \%$ of patients had an ABG measured during their ED stay and the median time to availability of $A B G$ results was greater than one hour. Point of care ABG analysis was unavailable at the participating EDs. Of concern was the number of traumatic brain injured patients with a $\mathrm{PaCO}_{2}$ less than 30 and greater than $49 \mathrm{mmHg}$ on initial measurement. Studies indicate $\mathrm{PaCO}_{2}$ levels in this range result in increased mortality $[34,35]$.

\section{Limitations}

This study was conducted in four centers representing inner city, high volume EDs, two of which provided regionalized trauma services to the province of Ontario. Our findings may not be generalizable to other centers and countries that may vary in their ability to provide care to ventilated patients and experience differences in patient and staffing profiles, ED LOS, and access block. RTs were asked to identify the primary reason for mechanical ventilation at the time of initiation from a predefined list and reasons for ED discharge delay introducing the potential for subjective assessments. Notwithstanding, reasons for ventilation were checked against ED discharge diagnoses and occurrence of ED discharge delay was confirmed in ED information systems. Due to the observational nature of the study, other confounding factors may have influenced ED LOS that were not accounted for in multivariate analyses. As well we could not examine the relationship between hospital mortality and ED LOS in the absence of a reliable ED illness severity score.

\section{Conclusions}

While patients requiring mechanical ventilation represent a small proportion of the total ED presentations they are not an infrequent event and many experienced an ED LOS $>24 \mathrm{~h}$. This finding raises concerns about the potential impact on patient safety and the quality of care received by critically ill patients in the ED and suggests a need for education for the ED team on management of ventilation beyond initial stabilization. ED discharge delays occurred more frequently for patients receiving NIV in the ED suggesting the need for review of admission pathways for these patients and consideration for provision of NIV on general floors.

\section{Abbreviations \\ ABG: Arterial blood gas; Cl: Confidence interval; CTAS: Canadian triage and acuity scale; ED: Emergency department; ICU: Intensive care unit; IQR: Interquartile range; LOS: Length of stay; NIV: Non-invasive ventilation; OR: Odds ratio; RR: Relative risk; RT: Respiratory therapist.}

\section{Competing interests}

The authors have no potentially conflicting personal or financial interests to be declared.

\section{Author contributions}

$L R, S G, K B, A W$, JL conceived the study, LR coordinated data collection and managed the data entry process, AK performed data analyses, all authors contributed to interpretation of the data, manuscript drafts and have read and approved the final manuscript.

\section{Financial support}

Canadian Association of Emergency Physicians and the Canadian Institutes of Health Research Partnerships in Health Service Improvement. Dr. Burns holds a Clinician Scientist award from the Canadian Institutes of Health Research.

\section{Acknowledgement}

This study was made possible by the Respiratory Therapy and Emergency Department staff of the four participating institutions. We would specifically like to thank Glen Bandiera, Sandi Ellis, Karen Gaunt, Pam Greco, Jocelyn Hurst, Ginny Martins, Margaret Oddi, Kerri Porretta, Sharon Ramagnano, Julie Spence, and Christina Sperling.

\section{Author details}

'Lawrence S. Bloomberg Faculty of Nursing, 155 College St, Rm 276, Toronto, ON M5T IP8, Canada. ${ }^{2}$ Departments of Emergency Medicine and Critical Care, St Michaels Hospital, 30 Bond St, Toronto, ON M5B 1W8, Canada.

${ }^{3}$ Department of Critical Care, St Michaels Hospital, 30 Bond St., Toronto, ON M5B 1W8, Canada. ${ }^{4}$ Department of Trauma, Emergency and Critical Care, Sunnybrook Health Sciences Centre, 2075 Bayview Ave., Toronto, ON M4N 3M5, Canada. ${ }^{5}$ Department of Research Design and Biostatistics, Sunnybrook Health Sciences Centre, 2075 Bayview Ave, Toronto, ON M4N 3M5, Canada. ${ }^{6}$ Department of Emergency Medicine, Hamilton Health Sciences \& McMaster University, 1200 Main St, West Hamilton, L8N 3Z5, Canada.

Received: 25 January 2012 Accepted: 1 April 2012

Published: 11 April 2012 


\section{References}

1. Tilluckdharry L, Tickoo S, Amoateng-Adjepong Y, Manthous C: Outcomes of critically ill patients based on duration of emergency department stay. Am J Emerg Med 2005, 23:336-339.

2. Chalfin D, Trzeciak S, Likourezos A, Baumann B, Dellinger R: Impact of delayed transfer of critically ill patients from the emergency department to the intensive care unit. Crit Care Med 2007, 35:1477-1483.

3. Jayaprakash N, O'Sullivan R, Bey T, Ahmed S, Lotfipour S: Crowding and delivery of healthcare in emergency departments: the European perspective. West J Emerg Med 2009, 10:233-239.

4. Lambe S, Washington D, Fink A, Herbst K, Liu H, Fosse J, Asch S: Trends in the use and capacity of California's emergency departments 1990-1999. Ann Emerg Med 2002, 39:389-396.

5. Herring A, Wilper A, Himmelstein D, Woolhandler S, Espinola J, Brown D, Camargo C: Increasing length of stay among adult visits to US emergency departments, 2001-2005. Acad Emerg Med 2009, 16:609-616.

6. Hsiao CJ, Cherry DK, Beatty PC, Rechtsteiner EA: National Hospital Ambulatory Care Survey: 2007 emergency department summary. National Health Statistics Reports 2010: no27. Hyattsville, MD: National Center for Health Statistics.

7. Ghosh R, Pepe P: The critical care cascade: a systems approach. Curr Opin Crit Care 2009, 15:279-283.

8. Cline S, Schertz R, EC F: Expedited admission of patients decreases duration of mechanical ventilation and shortens ICU stay. Am J Emerg Med 2009, 27:843-846

9. Grap M, Munro C, Unoki T, Hamilton V, KR W: Ventilator-associated Pneumonia: The Potential Critical Role of Emergency Medicine in Prevention. J Emerg Med 2010 Aug 6. [Epub ahead of print]

10. Lyneham J, Cloughessy L, Martin V: Workloads in Australian emergency departments a descriptive study. Int Emerg Nurs 2008, 16:200-206.

11. Beveridge R, Clarke B, Janes L, Savage N, Thompson J, Dodd G: Canadian Emergency Department Triage and Acuity Scale: implementation guidelines. CJEM 1999, 1: (3 suppl). Online version available at: http://caep. ca/template.asp?id=B795164082374289BBD9C1C2BF4B8D32

12. Unger B, Afilal M, Boivin J, Bullard M, Grafstein E, Schull M, Lang E, Colacone A, Soucy N, Xue X, et al: Development of the Canadian Emergency Department Diagnosis Shortlist. CJEM 2010, 12:311-319.

13. Hosmer DW, Lemeshow S: Applied Logistic Regression. 2nd edition. Philadelphia: Wiley-interscience; 2000.

14. Fromm R, Gibbs L, McCullum W, Niziol C, Babcock J, Gueler A, Levine R: Critical care in the emergency department: a time-based study. Crit Care Med 1993, 21:970-976.

15. Varon J, Fromm R, Levine R: Emergency department procedures and length of stay for critically ill medical patients. Ann Emerg Med 1994, 23:546-549

16. Clark K, Normile L: Delays in implementing admission orders for critical care patients associated with length of stay in emergency departments in six mid-atlantic states. J Emerg Nurs 2002, 28:489-495.

17. Dent A, Weiland T, Paltridge D: Australasian emergency physicians; a learning and educational needs analysis. Part Four: CPD topics desired by emergency physicians. Emerg Med Aust 2008, 20:260-266.

18. Parkhe M, Myles $P$, Leach $D$, Maclean A: Outcome of emergency department patients with delayed admission to an intensive care unit. Emerg Med 2002, 14:50-57.

19. Spirivulis P, Da Silva J, Jacobs I, Frazer A, Jelinek G: The association between hospital overcrowding and mortality amoung patients admitted via Western Australian emergency departments. Med J Aust 2006, 184:208-212

20. Schull MJ, Morrison LJ, Vermeulen M, Redelmeier DA: Emergency department overcrowding and ambulance transport delays for patients with chest pain. CMAJ 2003, 168:277-283.

21. Richardson DB: Increase in patient mortality at 10 days associated with emergency department overcrowding. Med J Aust 2006, 184:213-216.

22. Richardson DB: The access-block effect: relationship between delay to reaching an inpatient bed and inpatent length of stay. Med J Aust 2002, 177:492-495.

23. Schull M, Lazier K, Vermeulen M, Mawhinney S, Morrison L: Emergency department contributors to ambulance diversion: a quantitative analysis. Ann Emerg Med 2003, 41:467-476.

24. Pines J, Localio A, Hollander J, Baxt W, Lee H, Phillips C, Metlay J: The impact of emergency department crowding measures on time to antibiotics for patients with community-acquired pneumonia. Ann Emerg Med 2007, 50:510-516.

25. Esteban A, Ferguson N, Meade M, Frutos-Vivar F, Apezteguia C, Brochard L, Raymondoa K, Nin N, Hurtado J, Tomicic V, et al: Evolution of mechanical ventilation in response to clinical research. Am J Respir Crit Care Med 2008, 177:170-177.

26. Rocker G, Cook D, Sjokvist P, Weaver B, Finfer S, McDonald E, Marshall J, Kirby A, Levy M, Dodek P, et al: Clinician predictions of intensive care unit mortality. Crit Care Med 2004, 32:1149-1154.

27. Jones A, Fitch M, Kline J: Operational performance of validated physiologic scoring systems for predicting in-hospital mortality among critically ill emergency department patients. Crit Care Med 2005, 33: 974-978.

28. Gajic O, Frutos-Vivar F, Esteban A, Hubmayr R, Anzuetto A: Ventilator settings as a risk factor for acute respiratory distress syndrome in mechanically ventilated patients. Intensive Care Med 2005, 31:922-926.

29. Prella M, Feihl F, Domenighetti G: Effects of short-term pressure-controlled ventilation on gas exchange, airway pressures, and gas distribution in patients with acute lung injury/ARDS. Chest 2002, 122:1382-1388.

30. Davis K, Branson RD, Campbell RS, Porembka D: Comparison of volume control and pressure control ventilation: is flow waveform the difference. J Trauma 1996, 41:808-814.

31. Burns K, Adhikari N, Slutsky A, Guyatt G, Villar J, Zhang H, Zhou Q, Cook D, Stewart T, Meade M: Pressure and volume limited ventilation for the ventilatory management of patients with acute lung injury: a systematic review and meta-analysis. PLoS One 2011, 6:e14623.

32. ARDSnet: Ventilation with lower tidal volumes compared with traditional tidal volumes for acute lung injury and the acute respiratory distress syndrome. N Engl J Med 2000, 342:1301-1308.

33. Blonshine S, Foss C, Mottram C, Ruppal G, Wagner J: Blood gas analysis and hemoximetry: 2001 revision and update. Respir Care 2001, 46: 498-505.

34. Davis D, Idris A, Sise M, Kennedy F, Eastman A, Velky T, Vilke G, Hoyt D: Early ventilation and outcome in patients with moderate to severe traumatic brain injury. Crit Care Med 2006, 34:1202-1208.

35. Warner K, Cuschieri J, Copass M, Jurkovich G, Bulger E: Emergency department ventilation effects outcome in severe traumatic brain injury. J Trauma 2008, 64:341-347.

doi:10.1186/1757-7241-20-30

Cite this article as: Rose et al.: Emergency department length of stay for patients requiring mechanical ventilation: a prospective observational study. Scandinavian Journal of Trauma, Resuscitation and Emergency Medicine 2012 20:30.

\section{Submit your next manuscript to BioMed Central and take full advantage of:}

- Convenient online submission

- Thorough peer review

- No space constraints or color figure charges

- Immediate publication on acceptance

- Inclusion in PubMed, CAS, Scopus and Google Scholar

- Research which is freely available for redistribution 